\title{
Tool-Workpiece Interaction in the Cutting Process and Its Use
}

\author{
Karol Vasilko, Zuzana Murčinková \\ Technical University of Košice, Faculty of Manufacturing Technologies with seat in Prešov, \\ Bayerova 1,080 01 Prešov, Slovakia
}

\begin{abstract}
The paper analyzes the influence of natural tool wear on parameters of chip shaping and machining forces and proposes the adjustment of tool geometry based on natural shape of crater wear to extend time of machining. The contact of the cutting tool and the workpiece at actual cutting speed is a complex physical process, the result of which is a specific shape and characteristics of the machined surface and the modification of tool cutting characteristics. Due to the fact that there is no existing cutting material which would resist wear in the conditions of working high stress and temperature, it is necessary to take into account that tool cutting conditions change with cutting time. This is caused by the change in tool geometry after its functional areas become worn out. One of the practical effects of those changes is gradual modification of machined surface geometry, its fortification, formation of residual stress, character of chip formation and shaping, the development of friction temperature and deformation in the zone of the contact of the tool and workpiece. This means that the cut part changes its characteristics. It is up to date to eliminate or at least mitigate this negative influence of tool wear based on the results of cutting.
\end{abstract}

Keywords - crater wear, flank wear, chip shaping, machining time, cutting force, tool life.

DOI: 10.18421/TEM104-33

https://doi.org/10.18421/TEM104-33

Corresponding author: Zuzana Murčinková, Technical University of Košice, Faculty of Manufacturing Technologies with seat in Prešov, Slovakia.

Email: zuzana.murcinkova@tuke.sk

Received: 09 June 2021.

Revised: 20 October 2021.

Accepted: 26 October 2021.

Published: 26 November 2021.

(cc)BY-NC-ND(C) 2021 Karol Vasilko \& Zuzana Murčinková; published by UIKTEN. This work is licensed under the Creative Commons Attribution-NonCommercial-NoDerivs 4.0 License.

The article is published with Open Access at www.temjournal.com

\section{Introduction}

Observation of the change of the shape of the cutting wedge in the course of its wear leads to the modification of the original considerations about the mechanism of chip and machined surface formation. It is necessary to take into consideration that the tool works for example for 60 minutes before it gets blunt. It can be considered to be sharp, i.e. when the face and flank have linear profile, only in the first minutes of its work. Its shape is considerably modified. However, all previous schemes of chip formation were based on the image of "ideal" cutting wedge shape, which does not correspond facts [1], [2], [3]. Most of the cutting time, the tool cutting wedge is worn and its shape does not correspond with the new tool. It can be considered to be "sharp" probably only in the first minute of its cutting work. Besides that, straight face is rarely used in tools, for instance when cast metal or other brittle material is cut, where elementary - crumbling chip is formed [4], [5]. Cutting process needs to be observed in the dynamics of a wearing tool [6], [7], [8]. Here an attempt to approach the cutting process with tribology is presented.

\section{Influence of Tool Wear on Results of Cutting- Chip Shaping}

In Figure 1, there is a photography of a metallographic thin section of the zone of chip formation obtained after a short time period of cutting [8]. The original rake angle was $-6^{\circ}$.

A facet on the face, Figure 1, which is the result of the "protection function" of the built-up edge or plastic deformation zone, can be seen. The original rake angle is preserved only in this part of the cutting wedge. At the place of forming crater wear, the rake angle is positive (in this case $+7^{\circ}$ ). An imprinto of the rounded cutting edge with the radius $r_{\mathrm{n}}$ can be seen. On the tool flank side, an abrasion area with the width $V B$. 


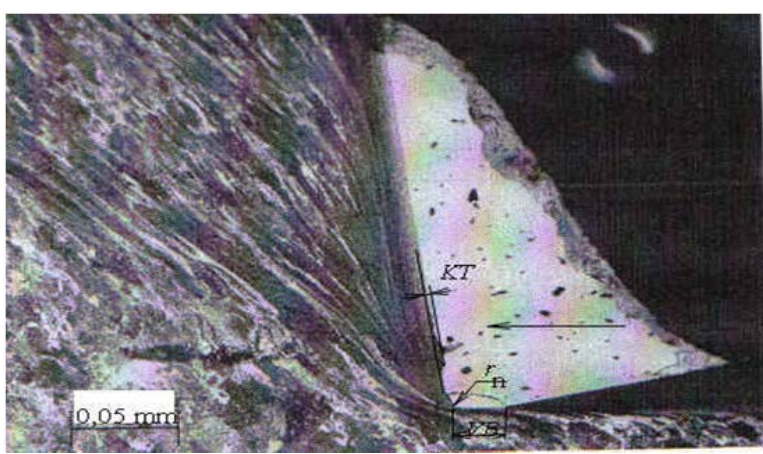

Figure 1. View of the chip creating process after short time period of cutting (5 min); KT is crater depth, $r_{\mathrm{n}}$ is nose radius, $V B$ is flank wear

Wear on the face of the tool and its shape has different influence on cutting process [9], [10]. Abrasion area on the flank has unambiguously negative influence on the growth of cutting forces, cutting temperature, and formation of oscillations in the machining system [11], [12]. However, the formation of the crater wear on the face can have positive effect. It increases the actual rake angle, by which the cutting force decreases and the chip is formed better.

The paper analyzes the chip shaping by the influence of the face crater wear. Figure 2 shows a change of crater wear profile measured in different machining phases. It can be seen that gradually the crater wear gets deeper and its center is shifted in the direction of the chip leaving. Behind the cutting edge, an area remains intact, its size and decline changes with wear. From the identification of the crater wear shape the course of standard stresses on the face can be reversely deduced. It can be supposed that larger material abrasion in the crater occurs in the place of higher stress, i.e. also transformed shear stress. Formation of the crater wear leads to visible change of actual tool rake angle. The results of measuring actual angles of face against the crater wear is shown in Table 1.

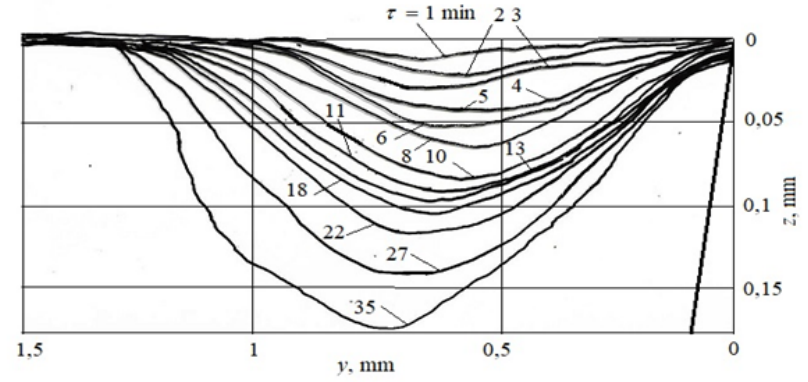

Figure 2. Gradual profiles of crater wear when turning;

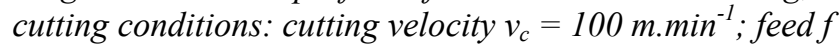

$=0,31 \mathrm{~mm}$; depth of cut $a_{p}=1 \mathrm{~mm}$; rake angle in orthogonal plane $\quad 0_{0}^{\circ}$; main cutting edge angle ${ }_{r}=$

$90^{\circ}$; inclination angle ${ }_{s}=0^{\circ}$; workpiece: steel 100CrMn6, tool: cemented carbide P20
Table 1. Increase of rake angle as a result of formation of face crater wear ( $\gamma_{\mathrm{n}}$ is rake angle in normal plane)

\begin{tabular}{|lccccc||}
\hline$\tau_{\mathrm{s},} \min$ & 1 & 2 & 4 & 6 & 10 \\
$\gamma_{\mathrm{n}}{ }^{\circ}$ & 1.5 & 3 & 4 & 6 & 12.5 \\
\hline$\tau_{\mathrm{s},} \min$ & 18 & 22 & 27 & 35 & \\
$\gamma_{\mathrm{n}}{ }^{\circ}$ & 15 & 16 & 20 & 25 & \\
\hline \hline
\end{tabular}

It can be seen that the actual rake angle changes and reaches large values. This fact has a superior influence on the process of chip formation, cutting forces and deformation phenomena in the area of chip creation and machined surface. At the same time, there occurs a more intense turning and in the final phase, also breaking of the chip. Table 2 presents chip shapes which were obtained during formation of crater wear. Gradually, the chip radius $r_{\mathrm{t}}$ and the chip volume coefficient $w\left(w=V_{\mathrm{ch}} / V_{\mathrm{m}} ; V_{\mathrm{ch}}\right.$ is volume of freely laid chips, $V_{\mathrm{m}}$ is volume of removed material) decrease that is the proof of the creation of „,natural chip shaper“ on the tool face.

Table 2. Chip shape and parameters forming the crater tool wear on face
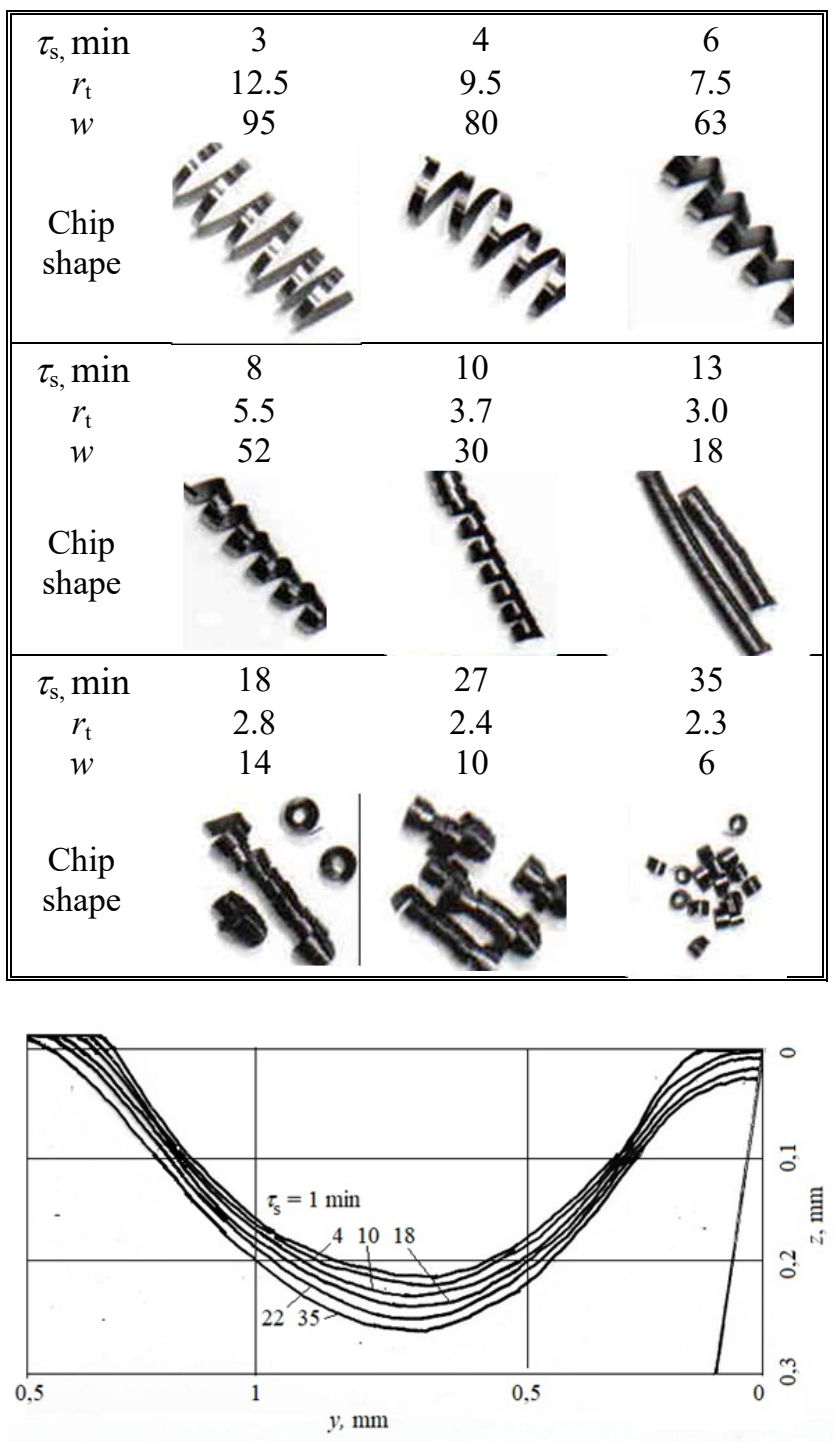

Figure 3. Changed crater wear shape when cutting with adjusted tool. Cutting conditions as in Figure 2 
A diamond grinding wheel was shaped according to shape of the final crater wear corresponding with time 35 minutes and the final shape of the crater wear was sharpened by it into the new adjusted tool. Identical tests of cutting have been performed with the tool and changes of the crater wear on the face measured. Corresponding the change of crater wear shape during cutting is shown in Figure 3.

As the crater wear gets bigger, it also gradually becomes evenly worn. This is the result of the fact that chip pressure on the bottom of the crater is evenly divided along the crater sides. From this position it is necessary to stress the tool face with linear face. The crater wear profile probably reflects the original distribution of stress on straight face. The intensity of the wear of such created crater wear is very small. The shape of the leaving chip corresponded with the last column in Table 2 and did not change in during cutting. Summary diagram in Figure 4 presents the wear of both tools (original and adjusted) and the changes of the radius of chip turning $r_{\mathrm{t}}$.

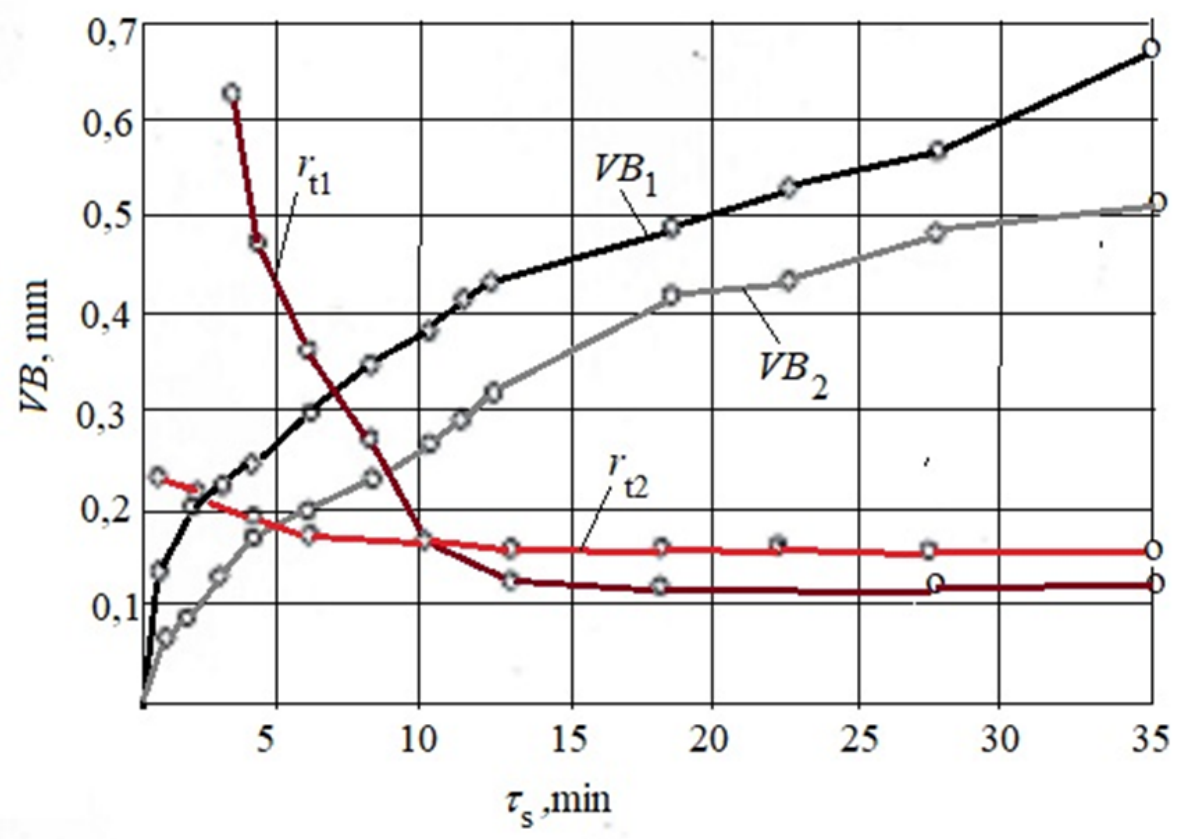

Figure 4. Flank wear $V B$ and the chip radius $r_{\mathrm{t}}$ in dependence of machining time $\tau_{\mathrm{S}} ; V B_{1}$ and $V B_{2}$ is flank wear of not adjusted (original) and adjusted cutting tool wedge, respectively, $r_{t 1}$ and $r_{t 2}$ is radius of chip cut by not adjusted and adjusted cutting tool

Flank wear of adjusted tool is smaller. It can be seen that the tool face crater wear has influence also on the abrasion of the tool flank side. The creation of the crater and the increase of the rake angle probably lead to the decrease of the stress on the tool flank side.

In the first phase of deepening crater on the tool face, the considerable decrease of the radius of chip compression occurs. In the presented case, the process stabilizes after approximately 10 minutes. It can be stated that there was some tool "test inrun". Next, the value of compression radius of turning stabilizes to a constant, very acceptable value.

Visibly milder course of dependence is recorded when cutting with the adjusted tool. Basically during all time of machining a well-shaped chip is formed.

Figure 5 provides the course of gradual increase of the depth of the crater on face of both tools. As it can be seen, the crater on the face of the adjusted tool does not increase or only minimally. On the contrary, the depth of crater sharply grows during the time of cutting with the tool with flat face surface.
It can be supposed that the crater would reliably shape the chip only at feed and depth of cut, at which it was formed. Therefore it is appropriate in the conditions of large serial production, where the cut material and cutting conditions do not change. With changing cutting conditions it is necessary to modify it or determine experimentally.

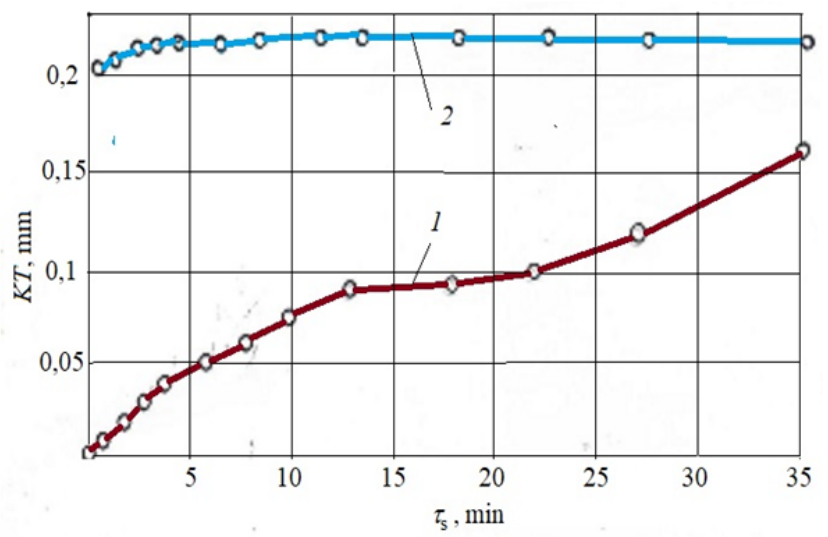

Figure 5. Increase of crater depth KT on tool face in dependence of machining time $\tau_{\mathrm{S}} .1$ - tool with flat face, 2 - tool with a adjusted crater on face 
Typical crater shapes, i.e., "natural chip shapers", on the fact at high degree of tool wear are shown in Figure 6.

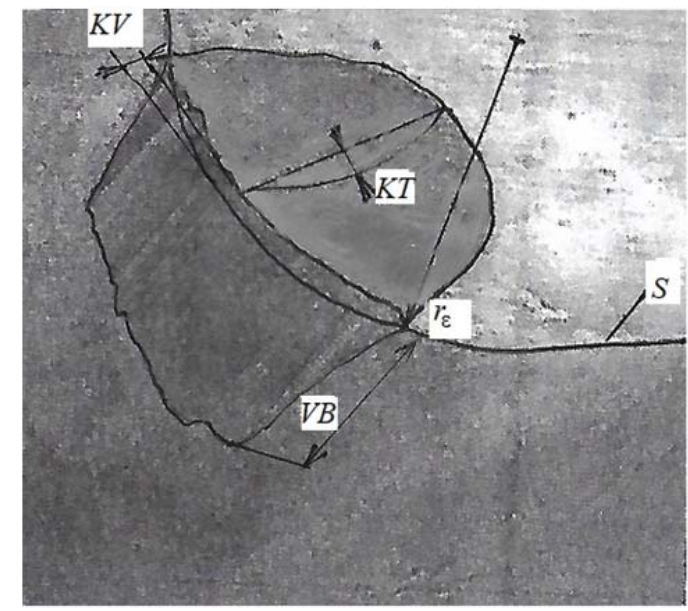

(a)

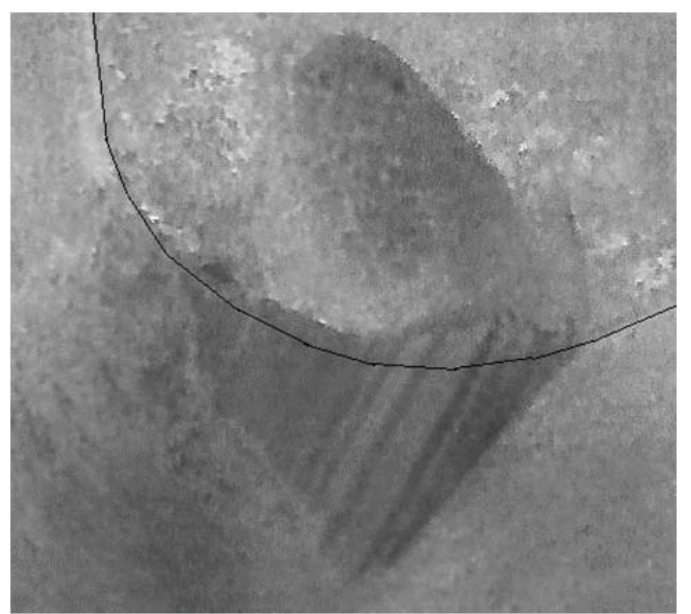

(b)

Figure 6. Photography of worn tool tips after extensive wear on the face and flank;(a) major cutting edge angle ${ }_{r}=$ $60^{\circ}$, (b), $\quad r=90^{\circ}, K T$ is crater depth, KV is radial displacement of the tool corner, VB is flank wear, $S$ is cutting edge, $r_{\varepsilon}$ is nose radius

In both cases, the crater is oriented in the direction of the chip leaving, which is different and depends on the major cutting edge angle $\kappa_{\mathrm{r}}$. One can notice, the radial displacement of the tool corner $K V$, crater and the flank wear land. The shape of the cutting edge is similar, but displaced due flank wear land on the flank face.

\section{Influence of Tool Wear on Results of Cutting - Cutting Forces}

It is interesting to observe the dependence of the components of cutting force depending on the tool wear. It can be supposed that the individual components should increase by the flank wear. However, if the tool would be worn only on the face, as it is presented above, the rake angle would grow and mainly the tangential cutting force $F_{\mathrm{c}}$ should decrease.

Figure 7 presents experimentally observed the tangential cutting force $F_{\mathrm{c}}$ depending on machining time $s$ in a case of both the face and flank wear. As a result, it can be seen that $F_{\mathrm{c}}$ is increasing for four different cutting velocities (i.e. $73,120,130,180$ $\left.\mathrm{m} \cdot \mathrm{min}^{-1}\right)$. Up to machining time approximately 9 minutes the tangential cutting force $F_{\mathrm{c}}$ corresponding with lowest cutting speed has the highest values. After that time, the opposite is true. To explain this effect, the presented dependence in Figure 7 is not sufficient.

It is obvious that the size of wear is not directly proportional with machining time. Therefore, the diagram has been transformed into a dependence $F=$ $\mathrm{f}(V B)$ shown in Figure 8. The experiment to obtain Figure 8 was performed until the tool was blunted.

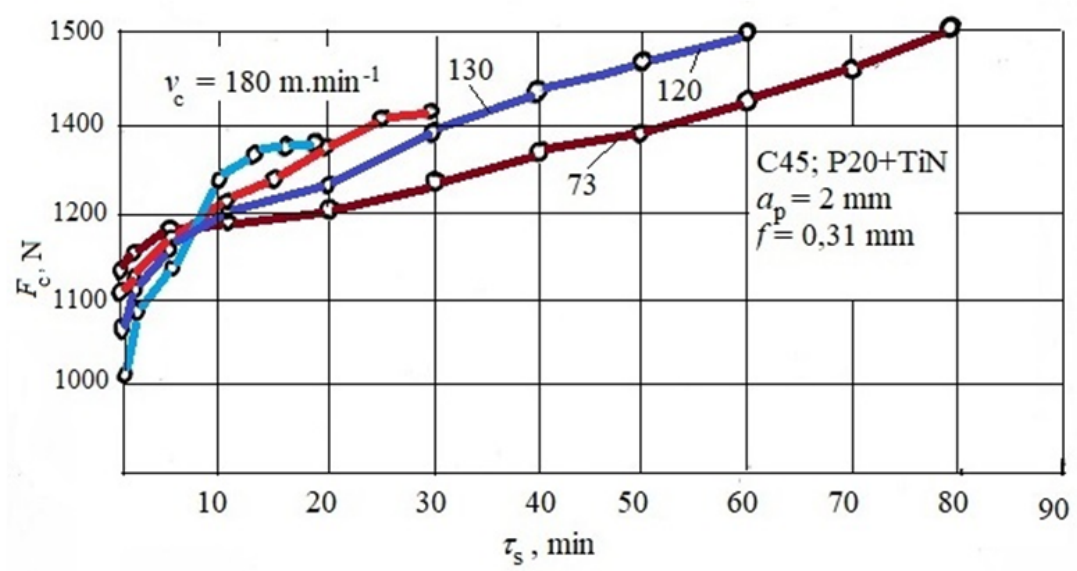

Figure 7. Experimental dependence of tangential cutting force $F_{\mathrm{c}}$ on machining time for four cutting velocity values 
It can be seen in Figure 8 that the character of the curve for cutting force $F_{\mathrm{c}}$ is similar to the characteristic curve of tool wear. Therefore it can be supposed that the size of that force is closely connected with the wear on the flank. Up to the flank wear of approximately $0.3 \mathrm{~mm}$ the cutting force $F_{\mathrm{c}}$ is smaller than feed cutting force $F_{\mathrm{f}}$. Then it is an opposite. Based on the above mentioned experiments results it can be assumed that when $V B=0.3 \mathrm{~mm}$ it is the moment of a significant crater creation on the tool face.

After blunting (in the presented case flank wear criterion $V B_{\mathrm{k}}=0.9 \mathrm{~mm}$ ) all three components of cutting force sharply grow. Thus the moment of tool blunting can be determined by indirect way by measuring the cutting forces.

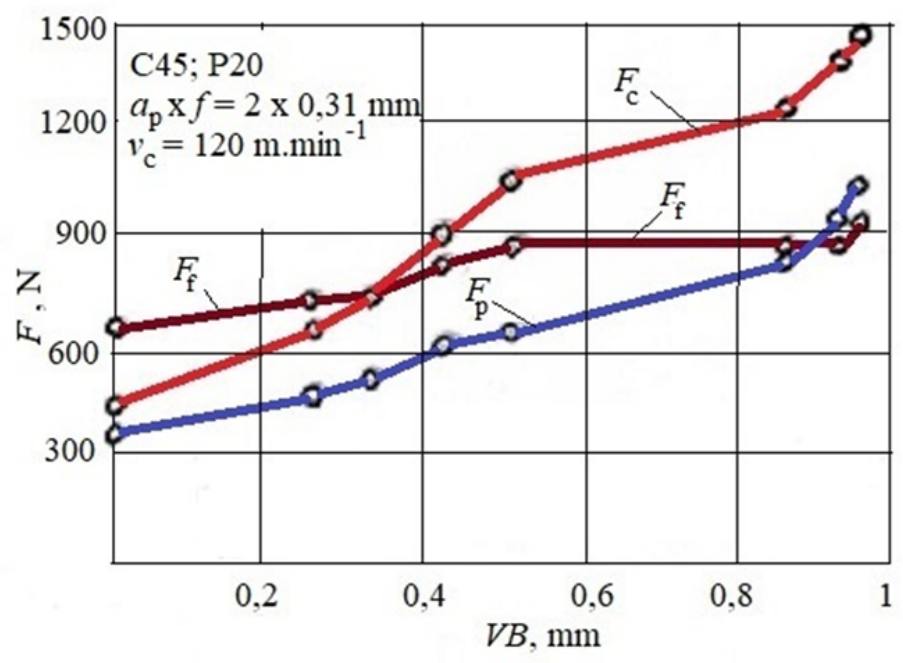

Figure 8. Experimental dependence of tangential, feed and passive $F_{\mathrm{c}}, F_{\mathrm{f}}, F_{\mathrm{p}}=\mathrm{f}(V B)$

\section{Conclusion}

When the tool interacts with the workpiece, gradual wear of functional areas of cutting tool occurs. This process is more intense in comparison with the friction of mechanical engineering parts in production machines. When creating wear, the geometry of cutting tool changes, and abrasion area on the flank part of the tool is formed as well as a crater caused by the chip leaving abrasion on the tool face. The analysis of that process has shown that the abrasion area on the tool flank has considerably negative influence on machining results mainly as a result of the increase of axial cutting force $F_{\mathrm{f}}$. On the other hand, the crater on the tool face influences machining process positively. It increases actual angle of tool face, stabilizes the pressure of the chip on worn face, gradually improves shaping of the chip. Thus a "natural chip shaper" is formed. A statement can be made that the best machining results are obtained after tool introduction "test inrun".

\section{Acknowledgements}

This work was supported by the Slovak Research and Development Agency under the Contact No. APVV-180316.

\section{References}

[1]. Buda, J., \& Békés, J. (1977). Teoretické základy obrábania kovov. Vydavatel'stvo tech. a ekonom. literatúry.

[2]. Degner, W., Lutze, H., Smejkal, E., Heisel, U., \& Rothmund, J. (2019). Spanende Formung: TheorieBerechnung-Richtwerte. Carl Hanser Verlag $\mathrm{GmbH}$ Co KG.

[3]. Granovskij, G. I. (1985). Granovskij VG Rezanie metallov. Moscow: Vysshaja shkola.

[4]. Kalpakjian, S. (2001). Manufacturing engineering and technology. Pearson Education India.

[5]. Trent, E. M., \& Wright, P. K. (2000). Metal cutting. Butterworth-Heinemann.

[6]. Kovač, P., \& Miličič, D. Rezanje metala Novi Sad: Univerzitet u Novom Sadu, 240 s. ISBN 86.899-00151.

[7]. Holešovský, F., \& Stančík, L. (1991). Materiály a technologie obrábění. Pedagoghická fakulta.

[8]. Vasilko, K., \& Mádl, J. (2012). Teorie obrábění (Theory of cutting). University of JE Purkyné, Ústinad Labem.

[9]. Dmochowski J. (1978). Podstawy obróbki skrawaniem. PWN, Warszawa.

[10]. Pelagić, Z., Nágel', M., Žmindák, M., \& Riecky, D. (2015). Wear simulation modeling by using the finite element method. Manufacturing technology, 15(2), 191-195.

[11]. Grzesik, W. (1998). Podstawy skrawania materiałów metalowych. Wydawnictwo Naukowo-Techniczne.

[12]. Weber, H., \& Loladze, T. N. (1986). Grundlagen des Spanens. Vlg Technik. 